\title{
In-Vitro Inhibition of Human Melanoma (BLM) Cell Growth by Progesterone Receptor Antagonist RU-486 (Mifepristone)
}

\author{
Pandurangan Ramaraj \\ Department of Biochemistry, Kirksville College of Osteopathic Medicine, A.T. Still University, Kirksville, MO, USA \\ Email: pramaraj@atsu.edu
}

How to cite this paper: Ramaraj, P. (2016) In-Vitro Inhibition of Human Melanoma (BLM) Cell Growth by Progesterone Receptor Antagonist RU-486 (Mifepristone). Journal of Cancer Therapy, 7, 1045-1058. http://dx.doi.org/10.4236/jct.2016.713101

Received: November 17, 2016 Accepted: December 20, 2016 Published: December 23, 2016

Copyright (@) 2016 by author and Scientific Research Publishing Inc. This work is licensed under the Creative Commons Attribution International License (CC BY 4.0).

http://creativecommons.org/licenses/by/4.0/

\begin{abstract}
RU-486 is an abortifacient which is used to terminate early pregnancy. It acts by blocking progesterone receptor. In our earlier study with progesterone, RU-486 was used as a progesterone receptor antagonist to find out the mechanism of progesterone action on melanoma cells. Results indicated that the effect of progesterone was not mediated through progesterone receptor. In the course of experiments, it was observed that RU-486 by itself inhibited mouse melanoma cell growth. Further research work with RU-486 showed a dose dependent inhibition of human melanoma cell growth. The mechanism of inhibition of cell growth was due to apoptosis and this effect of RU-486 was neither mediated through progesterone receptor nor glucocorticoid receptor. This in-vitro study suggested that melanoma also could be a target for RU-486 action, apart from breast, ovary and prostate cancers.
\end{abstract}

\section{Keywords}

Human Melanoma (BLM) Cell, RU-486, Apoptosis, Progesterone Receptor, Glucocorticoid Receptor

\section{Introduction}

Melanoma is a fatal form of skin cancer [1], which is on the rise. According to the American Cancer Society report [2], 76,380 new melanoma cases will be diagnosed and 10,130 people are expected to die from it this year (2016). This high number of death forced scientists to find drugs from various sources ranging from plant extract to snake venom [3] [4]. At this juncture, it is worth mentioning that our in-vitro study on melanoma cells with progesterone [5], revealed RU-486 ability to inhibit melanoma cell 
growth. RU-486 is a synthetic steroid and is a progesterone receptor antagonist [6]. RU-486 also binds to glucocorticoid receptor and is also considered as a glucocorticoid receptor antagonist [7]. RU-486 is used in the clinic to induce abortion during early pregnancy [8] and RU-486 is also used in the treatment of hormone dependent cancers such as breast, ovary and prostate [9] [10]. As stated earlier, present study with RU-486 was an extension of our previous work with progesterone, a female sex hormone. Previous study with progesterone showed that it inhibited mouse (B16F10) [11] and human melanoma (BLM) cell growth significantly in vitro and the mechanism of inhibition of human melanoma cell growth was due to autophagy [5]. In order to determine the mechanism of progesterone action, a bioassay involving co-incubation of progesterone with RU-486, a progesterone receptor antagonist, was carried out. Result indicated that progesterone action was not mediated through progesterone receptor. In addition, co-incubation of progesterone with RU-486 showed an additive effect on the inhibition of mouse as well as human melanoma cell growth, suggesting that the mechanism of actions of the two hormones might be different. Hence, the study was extended to check the effect of RU-486 alone on human melanoma (BLM) cell growth. Results showed that RU-486 inhibited human melanoma (BLM) cell growth significantly in a dose dependent manner. The mechanism of inhibition of human melanoma cell growth was due to apoptosis and RU-486 action was neither mediated through progesterone receptor nor through glucocorticoid receptor.

\section{Materials \& Methods}

Progesterone, RU-486, Dexamethasone, Pan-caspase inhibitor were all obtained from Sigma Chemical Company, St. Louis, MO. MTT (3-[4,5-Dimethylthiazol-2-yl]-2,5-diphenyl tetrazolium bromide), DAPI (4',6 diamidino-2-phenylindole), trypan blue, isopropanol, spermidine, 3-methyladenine, agarose were also obtained from Sigma Chemical Company. Caspase-3/7 assay kit (Apo-one homogenous caspase 3/7 assay) and TUNEL assay kit (DeadEnd colorimetric apoptosis detection system) were purchased from Promega, Madison, WI. Fetal bovine serum (FBS), Trypsin-EDTA (1×), and PBS powder were purchased from Atlanta biologicals, Lawrenceville, GA. RPMI and antibiotic/antimycotic solution $100 \times(10,000 \mathrm{IU} / \mathrm{ml}$ penicillin, $10 \mathrm{mg} / \mathrm{ml}$ streptomycin, $25 \mu \mathrm{g} / \mathrm{ml}$ amphotericin B) were purchased from Fisher scientific, Houston, TX. SLT Spectra plate reader was used for quantitation of cell growth by MTT assay.

\subsection{Growth Medium (GM)}

All cell culture works were carried out in RPMI 1640 medium containing 10\% FBS +1X Pen/Strep/Ampho [5], [11]. Cell growth was quantitated by MTT proliferation assay.

\subsection{MTT Proliferation Assay [12]}

BLM cells were suspended in growth medium (GM) and plated at a density of $1 \times 10^{4}$ cells/well in a 96 well plate. Cells were left overnight at $37^{\circ} \mathrm{C}$ to attach to the plate. Fol- 
lowing day, growth medium was replaced by GM containing hormones at different concentrations and incubated for $48 \mathrm{hrs}$. After $48 \mathrm{hrs}$, medium was replaced by $100 \mu \mathrm{l}$ of 1 in 10 diluted (in GM) MTT solution and incubated for another $4 \mathrm{hrs}$ at $37^{\circ} \mathrm{C}$. After $4 \mathrm{hrs}$, MTT solution was removed. MTT was reduced by metabolically viable cells to a colored (purple) water insoluble formazan salt. The purple color precipitate was solubilized by adding $100 \mu \mathrm{l}$ of isopropanol and shaken for 20 - $30 \mathrm{~min}$ at room temperature. Intensity of resultant purple color was measured at $570 \mathrm{~nm}$ in a SLT spectra plate reader.

\subsection{Trypan Blue Staining [13]}

Trypan blue is a dye that does not interact with cell unless the cell membrane is damaged. Healthy, undamaged cells exclude the dye, but it is readily absorbed by damaged cells and renders them clearly visible under microscope. After $48 \mathrm{hrs}$ of incubation of BLM cells with RU-486, $100 \mu$ l of $0.4 \%$ trypan blue in PBS was added to the chamber slide containing $1 \times 10^{4}$ cells and incubated for $5 \mathrm{~min}$ at room temperature. Cells were washed with PBS to remove excess trypan blue dye and were examined under microscope. Only dead cells would take up the dye and appear as dark stained cells under microscope.

\subsection{DAPI Staining [14]}

DAPI is a blue fluorescent probe. DAPI stains nucleus specifically, with little or no cytoplasmic labeling. After $48 \mathrm{hrs}$ of incubation of BLM cells with RU-486, cells in the chamber slide were fixed with $2 \%$ paraformaldehyde for $20 \mathrm{~min}$. Cells were washed with PBS to remove paraformaldehyde. One hundred $\mu$ of 1 in 1000 diluted DAPI was added to the cells and was incubated in the dark for 5 min. Excess DAPI was removed by washing with PBS and was viewed under bright and fluorescent light.

\subsection{TUNEL Assay [15]}

TUNEL assay was performed to check DNA fragments arising out of apoptosis. Procedure was carried out as per manufacturer's protocol. Briefly, cells grown on slide were fixed with $4 \%$ paraformaldehyde and permeabilized with $0.2 \%$ Triton X-100. Labeled with TdT reaction mix and stained with $100 \mu \mathrm{l}$ of DAB and visualized under a light microscope.

\subsection{Agarose Gel Electrophoresis [16]}

Agarose gel (1.2\%) was made by mixing agarose in $1 \mathrm{X}$ TAE buffer. After cooling the solution, ethidium bromide was added to the solution and poured into the gel apparatus. Fifteen microgram of DNA was loaded on the well and ran at 100 volts till the bromophenol dye moved $3 / 4$ of the gel. The gel was photographed under UV light.

\subsection{Caspase-3/7 Assay [17]}

Caspase-3/7 is a critical executioner of apoptosis, as it is responsible for the proteolytic 
cleavage of many key proteins. Assays were carried out as per the manufacturer's protocol. Briefly, cells (25000 cell/well) were lysed with lysis buffer. Two X (2X) reaction buffer was added, followed by $2 \mathrm{X}$ substrate working solution was added. The plate was covered and incubated at room temperature for $30 \mathrm{~min}$. The plate was read at excitation wavelength of $499 \mathrm{~nm}$ and emission wavelength of $521 \mathrm{~nm}$.

\subsection{Pre-Incubation with Progesterone}

As there were conflicting reports on the physical presence of progesterone and estrogen receptors in various melanoma cell lines, the mechanism of RU-486 action was determined by a bioassay. A bioassay, which involved pre-incubation of melanoma cells with progesterone followed by RU-486 treatment, was carried out. In the pre-incubation experiment, melanoma cells were pre-treated with various concentrations of $(1,2.5,5,10$ $\mu \mathrm{M})$ of progesterone for 60 - $90 \mathrm{~min}$. Afterwards, RU-486 at various concentrations (10, $50,100 \mu \mathrm{M})$ were added and incubated for $48 \mathrm{hrs}$. At the end of $48 \mathrm{hrs}$, MTT assay was carried out.

\subsection{Co-Incubation with Dexamethasone}

Initially dose response curve of dexamethasone (Dex) was carried out on BLM cells for $48 \mathrm{hrs}$. Then $1 \mu \mathrm{M}$ dexamethasone was co-incubated with various concentrations of RU-486. Dose response curve of straight RU-486 treated cells was compared with dose response curve of Dex and RU-486 co-incubated BLM cells.

\section{Statistical Analysis}

All experimental points were carried out in triplicate ( 3 wells). Each experiment was repeated a minimum of three times to check for consistency in results. Each experimental point was expressed as Mean \pm SEM. Significance between any two experimental conditions was decided using student's " $t$ " test. Unpaired t-test was used to determine the $p$-values and a $p$-value of 0.05 or less was considered significant.

\section{Results}

\subsection{Dose and Time Dependent Inhibition of Human Melanoma (BLM) Cell Growth by RU-486}

Initially dose response curve was carried out with RU-486 starting from $100 \mathrm{nM}$ to 200 $\mu \mathrm{M}$ to find out RU-486 effect on human melanoma (BLM) cell growth. There were qualitative and quantitative changes. Qualitatively cell morphology was changed as shown in Figure 1(a). Quantitatively, there was a dose-dependent (sigmoidal) inhibition of human melanoma cell growth as shown in Figure 1(b). A linear decrease in cell growth was seen between $10 \mu \mathrm{M}$ and $100 \mu \mathrm{M}$ concentrations. Secondly, to optimize the length of incubation time, percentage of cell growth with a single concentration of RU-486 (50 $\mu \mathrm{M})$ was monitored at $6,12,24,48$ and $72 \mathrm{hrs}$ time points. A significant decrease in cell growth (43.7\%) was observed at $48 \mathrm{hrs}$ as shown in Figure 1(c). So, it was decided to incubate melanoma cells with RU-486 for $48 \mathrm{hrs}$. 
(a)

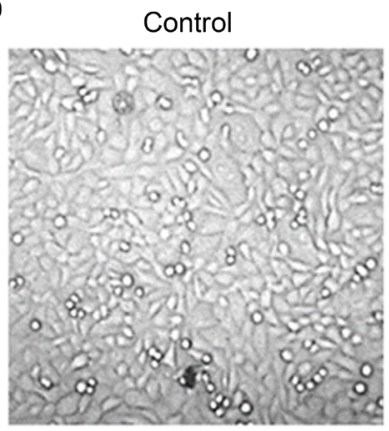

$\mathrm{RU}-10 \mu \mathrm{M}$

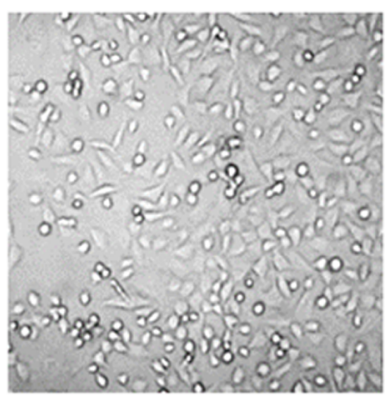

RU-50 $\mu \mathrm{M}$

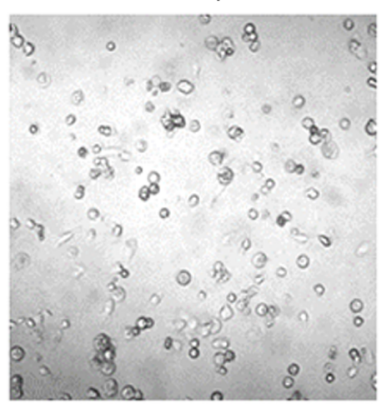

$\mathrm{RU}-100 \mu \mathrm{M}$

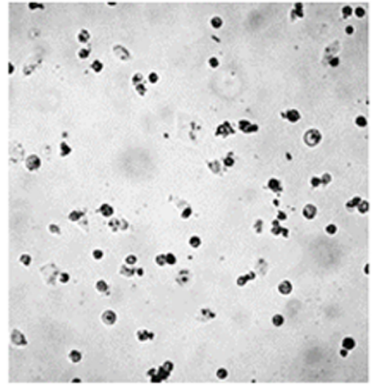

(b)

Dose-response curve

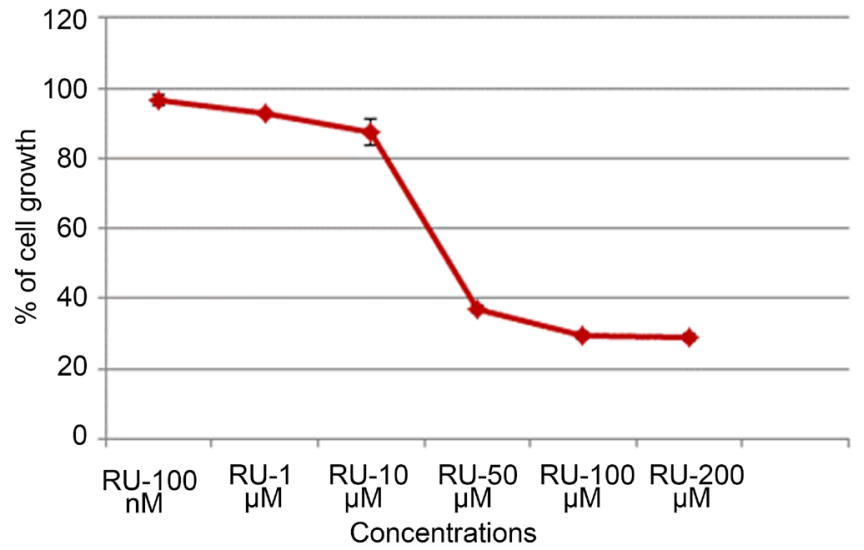

(c)

Time course curve

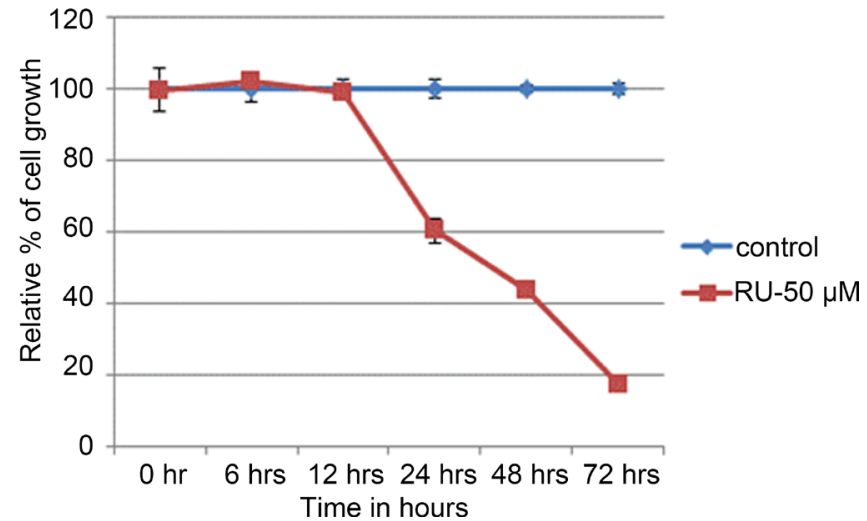

Figure 1. Dose-response and time-course curves: a) Effect of RU-486 at different concentrations on BLM cells were shown qualitatively by the microscopic pictures. b) Quantitative effect of RU-486 (100 nM to $200 \mu \mathrm{M})$ on BLM cell growth was shown by MTT proliferation assay. Both a and b showed dose-dependent decrease on cell growth with concomitant change in cell morphology. c) Time-course study using $50 \mu \mathrm{M}$ concentration of RU-486 showed significant inhibition of cell growth (43.7\%) at 48 hrs. For future study, 48 hrs of incubation time was used.

\subsection{Mechanism of Cell Death Induced by RU-486}

There was a significant decrease in melanoma cell growth with increasing concentrations of RU-486. There were also cells floating in the medium, suggesting cell growth inhibition was due to cell death. So, the mechanism of cell death was investigated.

\subsubsection{Autophagy Was Not the Cause of Cell Death}

Earlier work with progesterone showed that the mechanism of inhibition was due to autophagy [5]. So autophagy as the mechanism of cell death was checked by incubating BLM cells along with RU-486 and 3-methyladenine (1 mM). Three-methyladenine (3-MA) acts specifically on autophagic/lysosomal pathway and prevents the formation of autophagosomes [18]. In fact, 3-MA was used in another study to suppress autophagy in a mouse cell [19].

\subsubsection{Trial 3-MA Rescue}

In a trial experiment, autophagy was induced in BLM cells with spermidine, as spermi- 
dine was shown to induce autophagy in cells [20], [21]. One hundred $\mu \mathrm{M}$ of spermidine was added to the cells. Forty-eight hrs after incubation, MTT assay was carried out to quantitate cell growth. Cell growth was at $18 \%$ in spermidine treated cells (Figure 2(a)), compared to untreated control cell growth (100\%). However, addition of $1 \mathrm{mM}$ of 3-MA along with spermidine, partially rescued cell growth to $46 \%$ as shown in Figure 2(a).

\subsubsection{Co-Incubation of RU-486 with 3-MA}

In order to determine, whether autophagy was the mechanism of cell death, $1 \mathrm{mM}$ of 3-MA was added to various concentrations of RU-486 (1,10,50, 100 and $200 \mu \mathrm{M})$ and incubated for 48 hrs. Cell growth was quantitated by MTT assay after 48 hrs of incubation. There was no rescue of cell growth in 3-MA and RU-486 co-incubated cells compared to straight RU-486 treated cell growth (Figure 2(b)), suggesting autophagy was not the mechanism of cell death.

\subsection{Necrosis Was Not the Cause of Cell Death}

Cell death by Necrosis occurs when the cell membrane is ruptured. Necrosis is a process of cellular lysis with a corresponding release of cytoplasmic components into the surrounding tissue. Trypan blue dye could get into the cell and stain the dead cell. Viable cells would exclude trypan blue from inside. Trypan blue dye exclusion test was used to check if necrosis had taken place after RU-486 treatment. Trypan blue staining did not show any significant staining in the number of dead cells between untreated control and RU-486 treated cells (Figure 3), indicating necrosis was not the mechanism of inhibition of cell growth.

\subsection{Apoptosis Was the Cause of Cell Death}

Apoptosis, also known as programed cell death proceeds systematically. Chromatin condensation takes place followed by change in nuclear shape. So DAPI was used to stain the nucleus to check for change in nuclear shape.

\subsubsection{DAPI Staining}

When viewed under fluorescent microscope, DAPI staining showed crescent or sickle-shaped nuclei at various concentrations of RU-486 treated cells compared to untreated control cell nuclei (Figure 4(a)), suggesting the nuclear shape had been changed. This change in nuclear shape suggested that the mechanism of cell death could be due to apoptosis.

\subsubsection{TUNEL Assay}

In order to check for DNA fragments in the nucleus due to apoptosis, TUNEL assay was carried out as per manufacturer's protocol [15]. Dark brown stained nuclei were seen (Figure 4(b)). There were few brown color stained nuclei in control cells compared to RU-486 treated cells. Only few stained nuclei were seen at $100 \mu \mathrm{M}$ concentration of RU-486, because there were only few cells left after treatment with $100 \mu \mathrm{M}$ concentration of RU-486. Brown color staining of nuclei suggested the mechanism of cell death was due to apoptosis. 
Trial experiment with spermidine and 3-MA
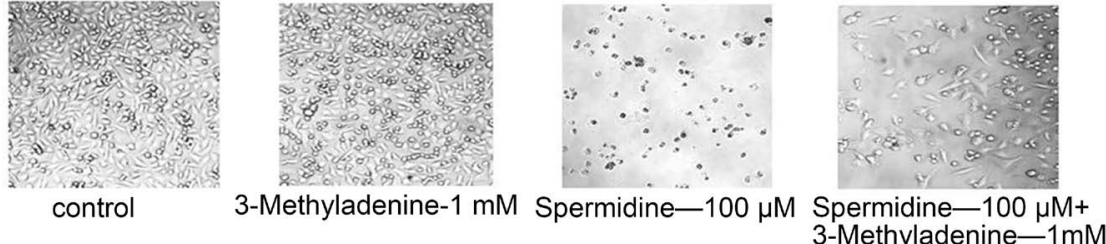

3-Methyladenine-1 mM Spermidine-100 $\mu \mathrm{M}$ Spermidine-100 $\mu \mathrm{M}+$
3-Methyladenine-1mM

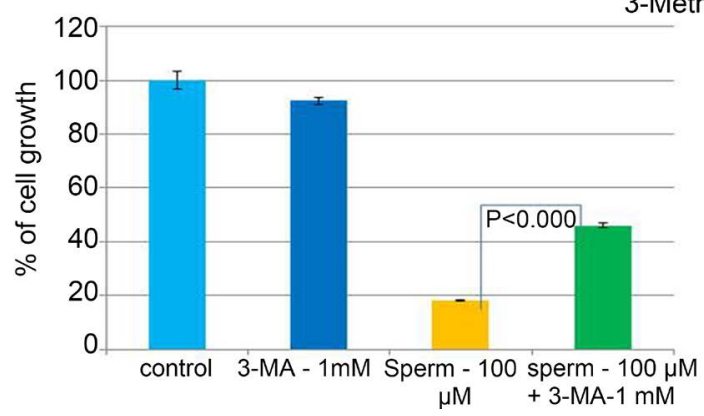

(a)

Experiment with progesterone and 3-MA

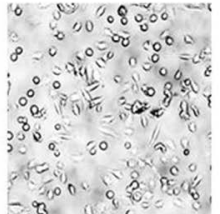

$\mathrm{RU}-10 \mu \mathrm{M}$

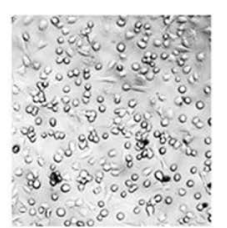

$\mathrm{RU}-10 \mu \mathrm{M}+3-\mathrm{MA}$

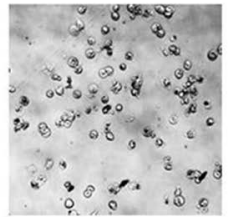

$\mathrm{RU}-10 \mu \mathrm{M}$

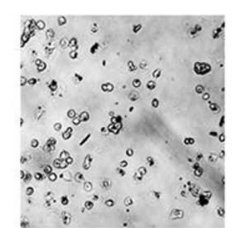

$\mathrm{RU}-10 \mu \mathrm{M}+3-\mathrm{MA}$

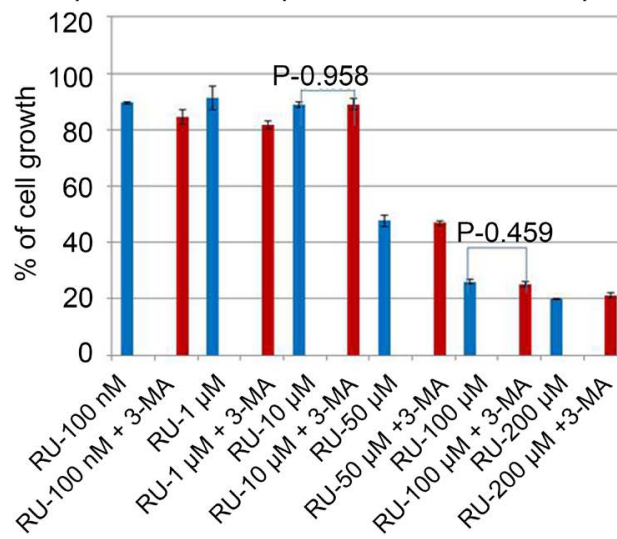

(b)

Figure 2. Mechanism of cell death-Autophagy: In order to investigate the mechanism of cell death, autophagy was induced in BLM cells with $100 \mu \mathrm{M}$ of spermidine and then $1 \mathrm{mM}$ of 3-MA was added along with spermidine. (a): In the trial experiment, cells were treated with $100 \mu \mathrm{M}$ of spermidine to induce autophagy. Then 3-MA at $1 \mathrm{mM}$ concentration was added along with spermidine to check if 3-MA was able to rescue cell death. As expected spermidine induced autophagy which was shown qualitatively by the microscopic picture and quantitatively by the MTT assay. However, addition of 3-MA was able to partially rescue cell death from autophagy as shown qualitatively by the microscopic picture and quantitatively by the MTT assay. (b): Same $1 \mathrm{mM}$ concentration of 3-MA was added to the experimental samples with RU-486 at different concentrations. As shown in the picture there was no change in cell morphology of 3-MA rescued cells compared to straight RU-486 treated cells. Again, quantitatively by MTT assay no difference was seen between RU-486 alone or 3-MA rescued cells. This experiment suggested that autophagy was not the mechanism of cell growth inhibition. 
Necrosis

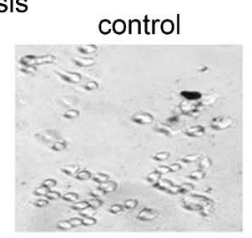

Mechanism of cell death

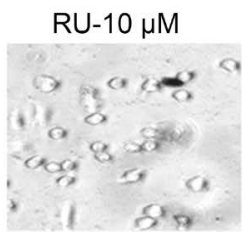

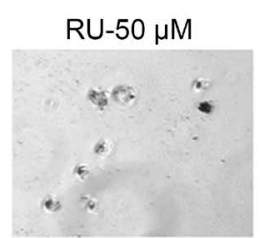

Figure 3. Mechanism of cell death-Necrosis: Necrosis as the possible mechanism of cell death was checked by carrying out trypan-blue dye exclusion test. Cells after $48 \mathrm{hrs}$ of treatment with RU-486 were incubated with $0.4 \%$ trypan blue dye for $5 \mathrm{~min}$ and then washed. Cells were examined under microscope for dead cells which took-up dark blue color staining. There was no significant difference in the number of stained cells between control and RU-486 treated cells, thus ruling out necrosis as the mechanism of cell death.

\subsubsection{Agarose Gel Electrophoresis}

As a follow-up study after DAPI and TUNEL staining, DNA was harvested from control and RU-486 treated $(10,50$ and $100 \mu \mathrm{M})$ cells and were analyzed by agarose gel electrophoresis. Ethidium bromide staining showed DNA ladder formation only in RU-486 treated cells, but not in control cells (Figure 4(c)), suggesting apoptosis as the mechanism of cell death. Though equal quantity of DNA was loaded, the bands were intense in $10 \mu \mathrm{M}$ RU-486 treated cells compared to 50 and $100 \mu \mathrm{M}$ treated cells. The reason could be based on the dose-dependent effect of RU-486 on BLM cells. Higher concentration resulted in more cell death than lower concentration treated cells. So, DNA fragmentation could be taking place slowly at lower concentration $(10 \mu \mathrm{M})$ than at 50 or $100 \mu \mathrm{M}$ treated cells at the time of harvesting cells after 48 hrs treatment with RU-486.

\subsubsection{Caspase-3/7 Assay}

Effector caspase-3/7 which brings about cleavage of proteins would be increased in apoptosis. So caspase-3/7 assay was carried out to determine if the activity of the enzyme was increased. Assay of caspase-3/7 activity showed a 2.5 fold increase in RU-486 $(50 \mu \mathrm{M})$ treated cells (Figure $4(\mathrm{~d})$ ) compared to untreated control cells ( $\mathrm{p}$ value $<0.01$ ), again indicating apoptosis as the mechanism of cell death.

\subsubsection{Partial Rescue of Cell Growth by Pan Caspase Inhibitor [17]}

Since, caspase activity was increased, then use of pan caspase inhibitor should be able to suppress apoptosis and could partially rescue cell growth. In fact, addition of $20 \mu \mathrm{M}$ of pan caspase inhibitor along with RU-486, partially rescued cell growth in RU-486 treated cells compared to plain RU-486 treated cells (Figure 4(e)), further providing evidence that cell death was due to apoptosis.

\subsection{RU-486 Mechanism of Action}

RU-486 is a synthetic steroid hormone and was shown to act through progesterone receptor [7] as well as glucocorticoid receptor [8]. Hence, it was important to study the mechanism of RU-486 action. 
Apoptosis

(a) Mechanism of cell death - Apoptosis
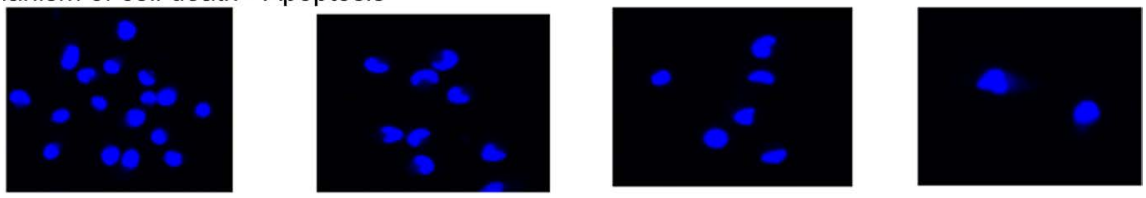

(b)-TUNEL assay
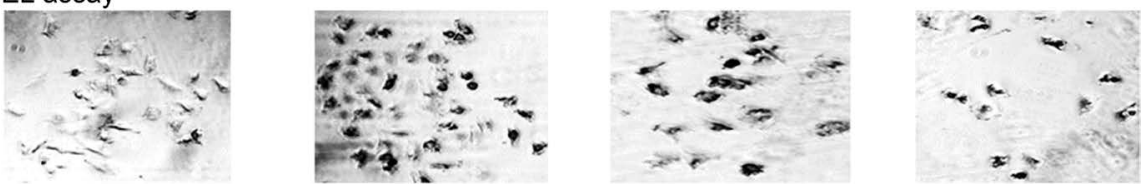

(c) Agarose gel electrophoresis

(d) 2.5 fold increase in caspase $3 / 7$ activity
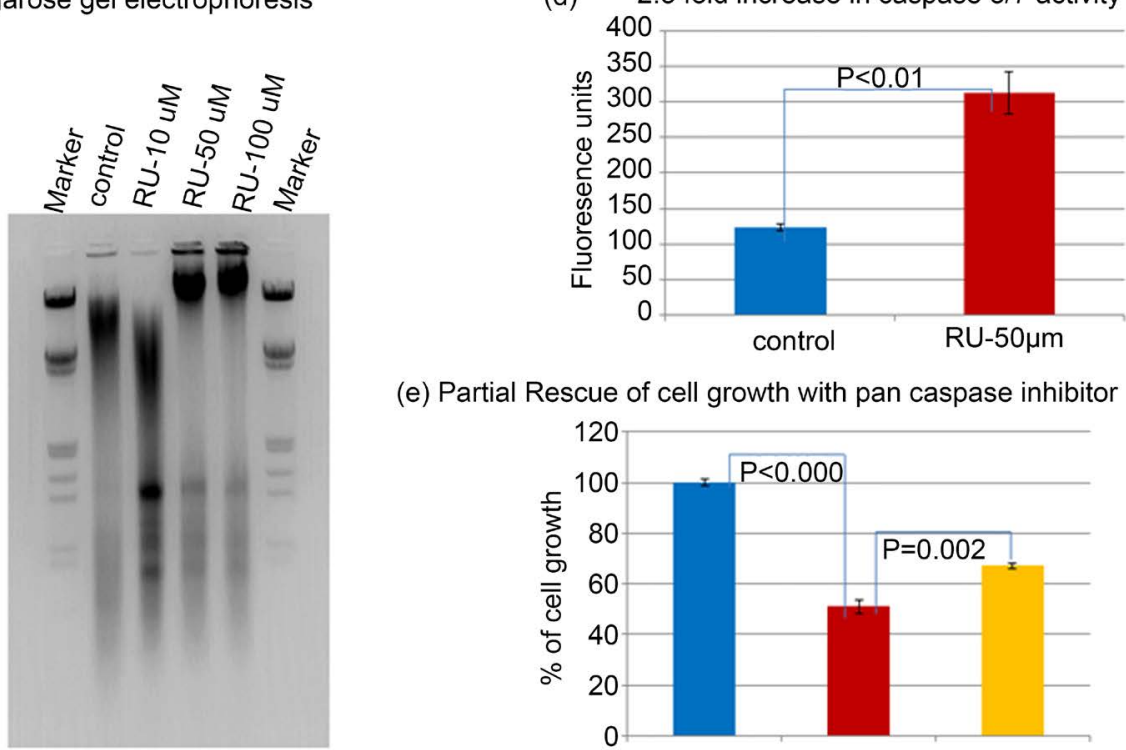

(e) Partial Rescue of cell growth with pan caspase inhibitor

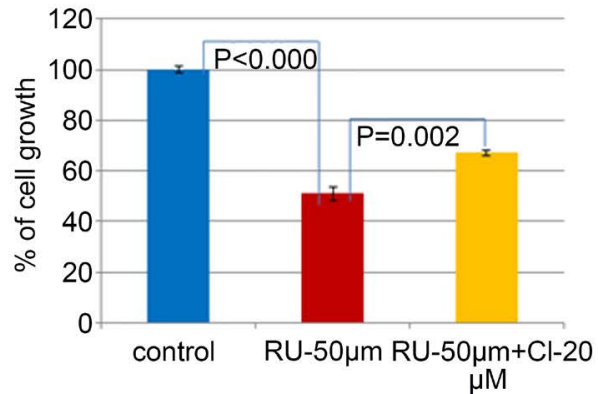

Figure 4. Mechanism of cell death-Apoptosis: (a): DAPI staining: Initially apoptosis as the mechanism of cell death was checked by looking for change in nuclear shape of RU-486 treated cells. The change in nuclear shape was visualized by staining with DAPI, which stained only nucleus. DAPI staining showed sickle-shaped or crescent-shaped cells in RU-486 treated cells, but not in untreated control cells. (b): TUNEL assay was carried out by following manufacturers protocol. Number of dark brown color stained cells was more in RU-486 treated cells than in control cells. At high concentration of RU-486 treatment, there were only few cells to start with, so only few cells were stained dark brown. Brown Staining indicated that the mechanism of cell death was due to apoptosis. (c): As a follow-up study, DNA was harvested from control and RU-486 treated cells and ran in $1.2 \%$ agarose gel at 100 volts. DNA ladder was seen in RU-486 treated cells, but not in control cells. Though equal quantity of DNA was loaded, the extent of damage to DNA and degradation of DNA could be more at higher concentration of RU-486, resulting in lighter DNA band at higher concentrations. (d): Since, the mechanism of cell death was due to apoptosis, the increase in effector caspase (caspase-3/7) activity was assayed for confirmation. There was a 2.5 fold increase in caspase-3/7 activity in RU-486 $(50 \mu \mathrm{M})$ treated cells compared to untreated control cells with a $\mathrm{P}$ value of less than 0.01 . This increase in caspase-3/7 activity suggested apoptosis as the mechanism of cell death. (e): As a confirmatory test for apoptosis, rescue of cell growth experiment using pan-caspase inhibitor (CI) was carried out. Prior to carrying out the experiment, a dose-curve was carried out to determine the optimal concentration of CI to use, which was $20 \mu \mathrm{M}$ of CI. Experiments showed that there was a partial rescue of cell growth by pan-caspase inhibitor. 
Mechanism of Steroid Action-Not Mediated through Progesterone Receptor

In the previous papers [5] [11] co-incubation study showed that the action of progesterone was not mediated through progesterone receptor. Yet another way to check the involvement of progesterone receptor was to pre-incubate BLM cells with progesterone at different concentrations $(1,2.5,5,10 \mu \mathrm{M})$ for $60-90 \mathrm{~min}$, followed by RU-486 treatment (Figure 5(a)). Progesterone would bind to progesterone receptor during the initial 60 - 90 min pre-incubation time and when RU-486 was added later, only very limited number of progesterone receptors would be available for RU-486 to act, resulting in an increased cell growth compared to straight RU-486 treated cells. However, the growth of progesterone pretreated cells followed by RU-486 treatment showed statistically significant decrease in cell growth compared to straight RU-486 treated cells (Figure 5(b)). This experiment not only suggested that both progesterone and RU-486 might be acting through different mechanism, but also indicated that RU-486 action was not mediated through progesterone receptor.

\subsection{Mechanism of Steroid Action-Not Mediated through Glucocorticoid Receptor}

Before carrying out co-incubation with RU-486, effect of Dex alone on BLM cell growth was determined by carrying out dose-response curve (Figure 6(a)), which did not show any dose-dependent effect on cell growth. In fact, it was a straight line, suggesting Dex had no effect on BLM cell growth. Then co-incubation of $1 \mu \mathrm{M}$ of Dex with varying concentrations of RU-486 was carried out. When the dose-response curve of straight RU-486 treated cells was compared with the dose-response curve of co-incubated cells (Figure 6(b)), there was no difference at all in their response, suggesting the action of RU-486 was not mediated through glucocorticoid receptor also.

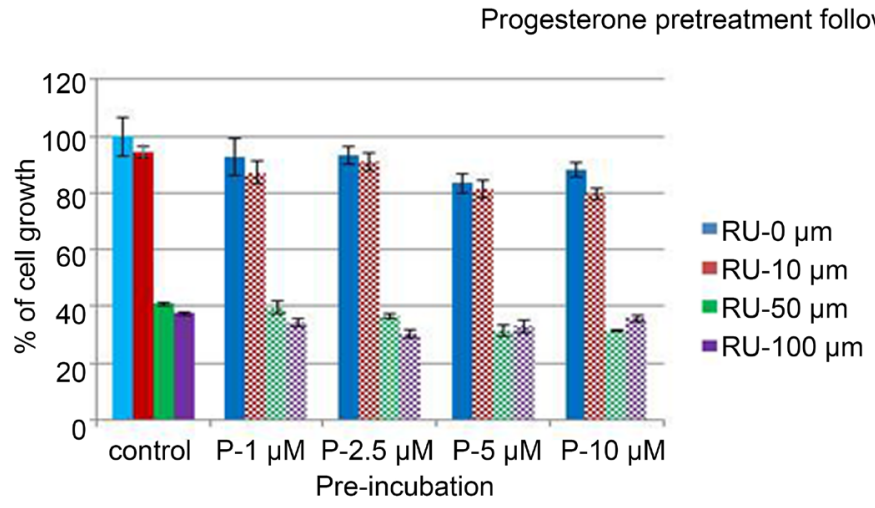

(a)

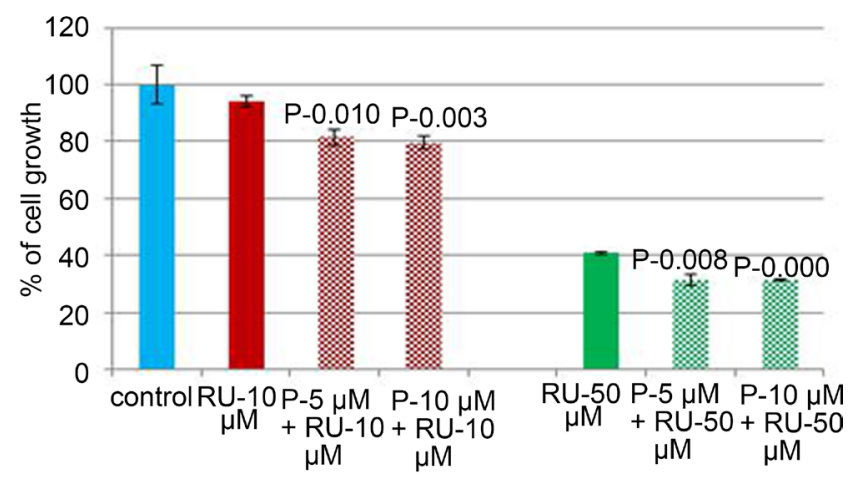

(b)

Figure 5. In order to study the mechanism of progesterone action, BLM cells were pre-incubated with progesterone ranging in concentrations from 1 to $10 \mu \mathrm{M}$ for 60-90 min. Afterwards cells were incubated with different concentrations of RU-486 (10, 50, 100 $\mu \mathrm{M})$. Generally, there was a decrease in cell growth (Figure 5(a)), suggesting the action was not mediated through progesterone receptor. In fact at P-5 $\mu \mathrm{M}$ and P-10 $\mu \mathrm{M}$ pre-treated cells, followed by RU-486-10 $\mu \mathrm{M}$ treatment, there was a statistically significant (P-0.010; 0.003) decrease in cell growth (Figure 5(b)), suggesting that RU-486 acted through different mechanism. Similarly, a statistically significant decrease in cell growth was observed at P-5 $\mu \mathrm{M}$ and P-10 $\mu \mathrm{M}$ pretreatment followed by RU-486-50 $\mu \mathrm{M}$ treatment (Figure 5(b)). 
Mechanism of RU-486 action - Glucocorticoid receptor

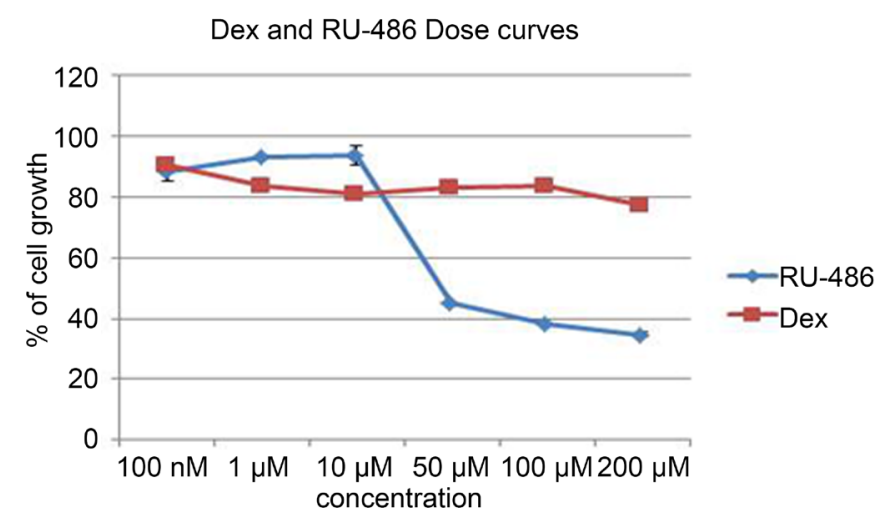

(a)

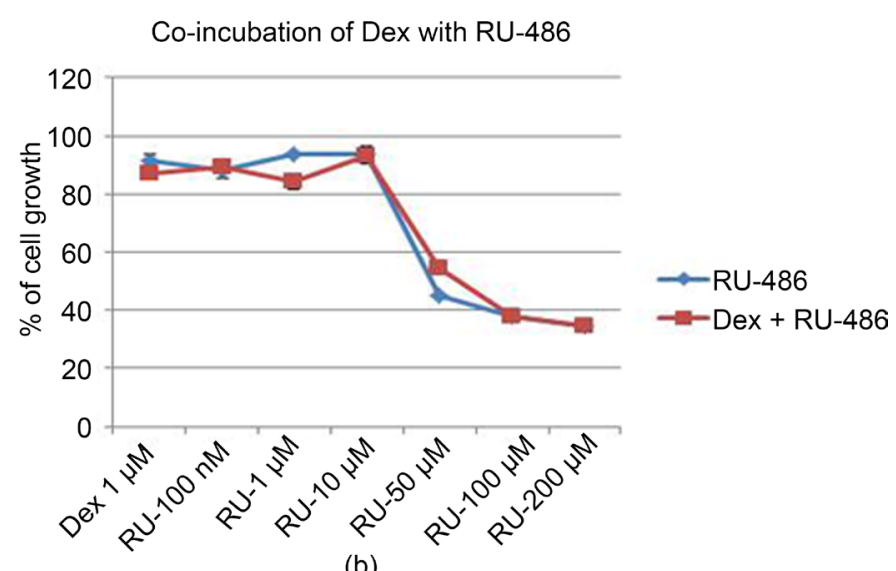

(b)

Figure 6. As RU-486 can also act through glucocorticoid receptor, it was essential to determine whether the action of RU-486 was mediated through glucocorticoid receptor. Initially cells were incubated with glucocorticoid receptor agonist dexamethasone (Dex), which showed a flat straight line compared to RU-486 dose curve (Figure 6(a)). Then cells were co-incubated with a fixed $1 \mu \mathrm{M}$ concentration of Dex and different concentrations of RU-486. The dose-response pattern of straight RU-486 treated cells was not different from Dex and RU-486 co-incubated cells dose-response pattern, suggesting glucocorticoid receptor was not involved.

\section{Discussion}

Present research work was an extension of our earlier work with progesterone, where progesterone was shown to inhibit human melanoma cell growth significantly and the mechanism of inhibition of cell growth was due to autophagy [5]. In order to study the mechanism of progesterone action, RU-486, a progesterone receptor antagonist was used. RU-486 did not compete with progesterone for progesterone receptor, instead exhibited additive effect on the inhibition of mouse melanoma cell growth [11]. So, the research work was extended to human melanoma (BLM) cell line. RU-486 showed a dose-dependent inhibition of human melanoma cell growth from $10 \mu \mathrm{M}$ to $100 \mu \mathrm{M}$ and an optimal incubation time of $48 \mathrm{hrs}$ of RU-486 treatment. As progesterone inhibited human melanoma cell growth by autophagy, initially mechanism of RU-486 inhibition of cell growth through autophagy was checked by co-incubating with 3-MA. Addition of 3-MA to RU-486 did not rescue BLM cells from cell death as expected, indicating autophagy was not the mechanism of cell death. Necrosis was ruled out by trypan blue dye exclusion assay. Finally apoptosis as the mechanism of cell death was checked first by DAPI staining of the nucleus, which showed a change in nuclear shape due to chromatin condensation, suggesting apoptosis could be the mechanism of cell death. Subsequently TUNEL assay, agarose gel electrophoresis, caspase 3/7 assay and partial rescue of cell growth by pan-caspase inhibitor were carried out. All experiments indicated that the mechanism of inhibition of cell growth was due to apoptosis. It was already reported that RU-486 had induced similar growth arrest, caspase activation and apoptosis in breast cancer cells [22]. So, RU-486 induced apoptosis in human melanoma (BLM) cells also. It was already reported by Dr. Telleria group [9] that other highly metastatic human cancer cell lines such as breast, ovary and prostate growth were also 
inhibited by RU-486.

Previous co-incubation study of progesterone with different concentrations of RU-486 showed that the action was not mediated through progesterone receptor [5] [11]. But, in the present study, cells were pre-incubated with different concentrations of progesterone $(1,2.5,5$ and $10 \mu \mathrm{M})$ and then followed by treatment with different concentrations of RU-486. Again there was no increase in cell growth, but only decrease in cell growth. Moreover, 10 and $50 \mu \mathrm{M}$ of RU-486 treatment after progesterone pretreatment showed further decrease in cell growth compared to straight RU-486 treated cells, suggesting the action of RU-486 was not mediated through progesterone receptor and the mechanism of action might be different. A Similar study by Fang et al. [23] also showed that the action of RU-486 was not mediated through progesterone receptor. Another study, where RU-486 action was not mediated through progesterone receptor had already been published [24]. Since, RU-486 is also a glucocorticoid receptor antagonist, the possibility of RU-486 acting through glucocorticoid receptor was checked. Initially, glucocorticoid receptor agonist dexamethasone alone was added to the cells at different concentrations. There was no dose response effect on cell growth. In fact, it was a straight line indicating dexamethasone had no effect on cell growth. Then co-incubation was carried out with 1 $\mu \mathrm{M}$ of dexamethasone and RU-486 at different concentrations. At the end of $48 \mathrm{hrs}$ incubation time, MTT assay revealed that there was no change in dose response curve when compared to straight RU-486 treated dose-response curve, suggesting the action was neither mediated through glucocorticoid receptor.

\section{Conclusion}

This in-vitro study showed that synthetic progesterone receptor antagonist RU-486 inhibited human melanoma cell growth significantly in a dose-dependent manner. The inhibition of cell growth was due to cell death by apoptosis and the action of RU-486 was mediated neither through progesterone receptor nor glucocorticoid receptor. This invitro study also suggested that melanoma could be a potential target for RU-486 action. An abortifacient's (RU-486) action on skin cancer without mediating through progesterone receptor was intriguing. It is interesting to note that neuroblastoma (nervous system) and melanoma (which is the cancer of melanocyte, derived from neural crest [25]) cell growth were inhibited by RU-486 without mediating through progesterone receptor.

\section{Acknowledgements}

This work was supported by a start-up research grant (grant \# 261-200-889) from KCOM and Warner/Fermaturo intramural research grant (grant \# 261-8530-501392) from A.T. Still University to P.R. Technical assistance in preparation of the manuscript by Sujatha Bhuvanaraj is duly acknowledged.

\section{References}

[1] Gray-Schopfer, V., Wellbrock, C. and Marais, R. (2007) Melanoma Biology and New Tar- 
geted Therapy. Nature, 445, 851-857. https://doi.org/10.1038/nature05661

[2] http://www.cancer.org/research/cancerfactsstatistics/cancerfactsfigures2016/

[3] Tan, Y.M., Yu, R. and Pezzuto, J.M. (2003) Betulinic Acid-Induced Programmed Cell Death in Human Melanoma Cells Involves Mitogen-Activated Protein Kinase Activation. Clinical Cancer Research, 9, 2866-2875.

[4] Vyas, V.K., Brahmbhatt, K., Bhatt, H. and Parmar, U. (2013) Therapeutic Potential of Snake Venom in Cancer Therapy: Current Perspectives. Asian Pacific Journal of Tropical Biomedicine, 3, 156-162. https://doi.org/10.1016/S2221-1691(13)60042-8

[5] Ramaraj, P. and Cox, J.L. (2014) In-Vitro Effect of Progesterone on Human Melanoma (BLM) Cell Growth. International Journal of Clinical and Experimental Medicine, 7, 39413953.

[6] Weiss, B.D. (1993) RU-486: The Progesterone Antagonist. Archives of Family Medicine, 2, 63-70. https://doi.org/10.1001/archfami.2.1.63

[7] Baulieu, E.E. (1991) The Steroid Hormone Antagonist RU-486: Mechanism at the Cellular Level and Clinical Applications. Endocrinology and Metabolism Clinics of North America, 20, 873-891.

[8] Ulmann, A. (1987) The Antiprogestins: A Recent Advance in Fertility Regulation. Journal of Steroid Biochemistry, 27, 1009-1012. https://doi.org/10.1016/0022-4731(87)90182-8

[9] Brandhagen, B.N., Tieszen, C.R., Ulmer, T.M., Tracy, M.S., Goyeneche, A.A. and Telleria, C.M. (2013) Cytostasis and Morphological Changes Induced by Mifepristone in Human Metastatic Cancer Cells Involve Cytotoskeletal Filamentous Actin Reorganization and Impairment of Cell Adhesion Dynamics. BMC Cancer, 13, 35.

https://doi.org/10.1186/1471-2407-13-35

[10] Taplin, M.E., Manola, J., Oh, W.K., Kantoff, P.W., Bubley, G.J., Smith, M., Barb, D., Mantzoros, C., Gelmann, E.P. and Balk, S.P. (2008) A Phase II Study of Mifepristone (RU-486) in Castration-Resistant Prostate Cancer, with a Correlative Assessment of Androgen-Related Hormones. BJU International, 101, 1084-1089. https://doi.org/10.1111/j.1464-410X.2008.07509.x

[11] Ramaraj, P. and Cox, J.L. (2014) In Vitro Effect of Sex Steroids on Mouse Melanoma (B16F10) Cell Growth. CellBio, 3, 60-71. https://doi.org/10.4236/cellbio.2014.32007

[12] Mosmann, T. (1983) Rapid Colorimetric Assay for Cellular Growth and Survival: Application to Proliferation and Cytotoxicity Assays. Journal of Immunological Methods, 65, 5563. https://doi.org/10.1016/0022-1759(83)90303-4

[13] Macleod, K.G. and Langdon, S.P. (2004) Viable Cell Counting Using Trypan Blue. In: Langdon, S.P., Ed., Cancer Cell Culture Methods and Protocols, Humana Press, Totowa, pp. 26.

[14] Li, X., Melmed, M.R. and Darzynkiewiz, Z. (1996) Detection of Apoptosis and DNA Replication by Different Labeling of DNA Strands with Fluorochromes of Different Cells. Experimental Cell Research, 222, 28-37. https://doi.org/10.1006/excr.1996.0004

[15] www.promega.com/resources/protocols/technical-bulletins/0/deadend-colorimetric-tunel-s ystem-protocol/

[16] Hughes, D. and Mehmet, H. (2003) Protocol 11.9: Detection of High Molecular Weight DNA Fragments by Gel Electrophoresis. In: Hughes, D. and Mehmet, H., Eds., Cell Proliferation \& Apoptosis, BIOS Scientific Publishers, Ltd., Oxford, 312.

[17] Nicholson, D.W., et al. (1995) Identification and Inhibition of the ICE/CED-3 Protease Necessary for Mammalian Apoptosis. Nature, 376, 37-43. https://doi.org/10.1038/376037a0

[18] Seglen, P.O. and Gordon, P.B. (1982) 3-Methyladenine: Specific Inhibitior of Autophag- 
ic/Lysosomal Protein Degradation in Isolated Rat Hepatocytes. Proceedings of the National Academy of Sciences, 79, 1889-1892. https://doi.org/10.1073/pnas.79.6.1889

[19] Jagannath, C., Lindsey, D.R., Dhandayuthapani, S., Xu, Y., Hunter, R.L.J. and Eissa, N.T. (2009) Autophagy Enhances the Efficacy of BCG Vaccine by Increasing Peptide Presentation in Mouse Dendritic Cells. Nature Medicine, 15, 267-276.

https://doi.org/10.1038/nm.1928

[20] Madeo, F., Eisenberg, T., Butner, S., Ruckenstuhl, C. and Kroener, G. (2010) Spermidine-A Novel Autophagy Inducer and Longevity Elixir. Autophagy, 6, 160-162. https://doi.org/10.4161/auto.6.1.10600

[21] Morselli, E., et al. (2011) Spermidine and Resveratrol Induce Autophagy by Distinct Pathways Converging on the Acetylproteome. The Journal of Cell Biology, 192, 615-629. https://doi.org/10.1083/jcb.201008167

[22] Gaddy, V., Barrett, J., Delk, J., Kallab, A., Porte, A. and Schoenlein, P. (2004) Mifepristone Induces Growth Arrest, Caspase Activation, and Apoptosis of Estrogen Receptor-Expressing, Antiestrogen-Resistant Breast Cancer Cells. Clinical Cancer Research, 10, 5215-5225. https://doi.org/10.1158/1078-0432.CCR-03-0637

[23] Fang, X., Zhang, X., Zhou, M. and Li, J. (2010) Effects of Progesterone on the Growth Regulation in Classical Progesterone Receptor-Negative Malignant Melanoma Cells. Journal of Huazhong University of Science and Technology [Medical Sciences], 30, 231-234. https://doi.org/10.1007/s11596-010-0220-3

[24] Atif, F., et al. (2011) Progesterone Inhibits the Growth of Human Neuroblastoma: In Vitro and in Vivo Evidence. Molecular Medicine, 17, 1084-1094. https://doi.org/10.2119/molmed.2010.00255

[25] Dupin, E. (2011) Phenotypic Plasticity of Neural Crest-Derived Melanocytes and Schwann Cells. Biologie Aujourd'hui, 205, 53-61. https://doi.org/10.1051/jbio/2011008

\section{Abbreviations}

MTT-3-[4,5-Dimethylthiazol-2-yl]-2,5-diphenyl tetrazolium bromide.

DAPI-4',6 diamidino-2-phenylindole; Dex-Dexamethasone.

TUNEL-TdT-mediated dUTP Nick-End Labeling.

3-MA-3-methyladenine; DAB-3,3'-Diaminobenzidine. 
Submit or recommend next manuscript to SCIRP and we will provide best service for you:

Accepting pre-submission inquiries through Email, Facebook, LinkedIn, Twitter, etc. A wide selection of journals (inclusive of 9 subjects, more than 200 journals)

Providing 24-hour high-quality service

User-friendly online submission system

Fair and swift peer-review system

Efficient typesetting and proofreading procedure

Display of the result of downloads and visits, as well as the number of cited articles

Maximum dissemination of your research work

Submit your manuscript at: http://papersubmission.scirp.org/

Or contact jct@scirp.org 